\title{
Evaluation of different machine learning methods for ligand-based virtual screening
}

\author{
R Kurczab, S Smusz, AJ Bojarski \\ From 6th German Conference on Chemoinformatics, GCC 2010 \\ Goslar, Germany. 7-9 November 2010
}

In silico High Throughput Screening of large compound databases has become increasingly popular technology of finding valuable drug candidates, by applying a wide range of computational methods, such as machine learning [1]. In recent years, many comparative studies of different machine learning methods performance in ligandbased virtual screening have been reported [2,3].

In order to extend these studies, we have evaluated over 60 different machine learning methods, such as: support vector machines (with and without parameter optimization), naïve Bayesian, decision trees, random forest, meta-classifiers (boosting, bagging, grading) and many others. All calculations were performed using a collection of machine learning algorithms for data mining implemented in WEKA package [4]. Additionally, for each of the method, we have examined the influence of different type of fingerprints, the size of training sets and attribute selection methods on the rate of active recall and precision of selection. Our internal database of known 5-HT7 antagonists has been used to build training and testing sets.

It was found that there is no machine learning approach that consistently provides the best results but some of them are very stable and can be applied universally.

\section{Acknowledgements}

The study was partly supported by a grant PNRF-103-Al-1/07 from Norway through the Norwegian Financial Mechanism.

Published: 19 April 2011

\footnotetext{
* Correspondence: kurczab@if-pan.krakow.pl Department of Medicinal Chemistry, Institute of Pharmacology Polish Academy of Sciences, Krakow, 31-343, Poland
}

\section{References}

1. Melvile J, Burke E, Hirst J: Machine Learning in Virtual Screening. Comb. Chem. High Throughput Screening 2009, 12:332-343.

2. Plewczynski D, Spieser S, Koch U: Performance of machine learning methods for ligand-based virtual screening. Comb Chem High Throughput Screening 2009, 12:358-368

3. Ma X, Jia J, Zhu F, Xue Y, Li Z, Chen Y: Comparative analysis of machine learning methods in ligand-based virtual screening of large compound libraries. Comb Chem High Throughput Screening 2009, 12:344-357.

4. Hall M, Frank E, Holmes G, Pfahringer B, Reutemann P, Witten I: The WEKA Data Mining Software. SIGKDD Explorations 2009, 11:10-18.

\section{doi:10.1186/1758-2946-3-S1-P41}

Cite this article as: Kurczab et al:: Evaluation of different machine learning methods for ligand-based virtual screening. Journal of Cheminformatics 2011 3(Suppl 1):P41.
Publish with ChemistryCentral and every scientist can read your work free of charge

"Open access provides opportunities to our colleagues in other parts of the globe, by allowing anyone to view the content free of charge."

W. Jeffery Hurst, The Hershey Company.

- available free of charge to the entire scientific community

- peer reviewed and published immediately upon acceptance

- cited in PubMed and archived on PubMed Central

- yours - you keep the copyright

Submit your manuscript here:

http://www.chemistrycentral.com/manuscript/

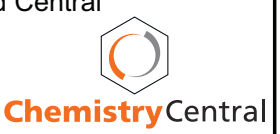

